\title{
The Relationship between Subjective Evaluation of Stressors and Depression in Menopausal Women: The Mediating Role of Life Satisfaction
}

\author{
Fatemeh Akbari $^{1}$, Shirin Farazmand ${ }^{2 *}$, Bahman Bahmani ${ }^{3}$ \\ 1. Family Research Institute, Shahid Beheshti University, Tehran, Iran \\ 2. Department of Clinical Psychology, University of Social Welfare and Rehabilitation Sciences, Tehran, Iran. \\ 3. Department of Counseling, University of Social Welfare and Rehabilitation Sciences, Tehran, Iran.
}

Citation: Akbari, F., Farazmand, Sh., \& Bahmani, B. (2016). The Relationship between Subjective Evaluation of Stressors and Depression in Menopausal Women: The Mediating Role of Life Satisfaction. Journal of Practice in Clinical Psychology, 4(3), 183-190. https://dx.crossref. org/10.15412/J.JPCP.06040306

http://dx.crossref.org/10.15412/J.JPCP.06040306

\section{Article info:}

Received: 23 Feb. 2016

Accepted: 19 May 2016

\section{Keywords:}

Life style, Stress, Menopause, Life satisfaction, Depression

\section{ABSTRACT}

Objective: Previous studies have shown that menopausal women are more likely to experience depression. However, there are few studies that investigated the cognitive mechanism that may have a role in developing depression in menopausal women. Thus, the present study aimed to investigate the mediating role of life satisfaction in the relation between subjective evaluation of stressors and depression in the middle-aged menopausal women.

Methods: This was a cross-sectional study. A total of 107 female staff were selected by available sampling method from women aged 47 to 58 years, who were working at Shaid Beheshti University. The participants completed the Beck depression inventory (BDI-II), Kern lifestyle scale (KLS), and the satisfaction with life scale (SWLS). The data were analyzed by path analysis using hierarchical regression analysis. All statistics were done by SPSS 16.

Results: The results indicated that subjective evaluation of stressors of control, self-esteem, and perfectionism that measured by KLS in menopausal women was associated with depression and mediated through their life satisfaction $(\mathrm{P}<0.01)$. The control, self-esteem, and perfectionism styles are indirect predictors of depression through life satisfaction.

Conclusion: Our findings suggested that subjective evaluation of stressors contributed to depression in menopausal women through affecting their life satisfaction. Objective sources of menopausal women stress (stressors) can be considered only as the potential sources of stress. These sources can lead to the real stress if the menopausal women perceives them as the threats to satisfaction of fundamental needs presented through their lifestyle.

\section{Introduction}

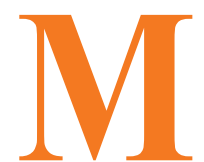

enopause is one of the most frequently studied life transition associated with middle-aged women (Lippert, 1997). Al- though, menopause is a natural life transition in women, yet it is not well understood. Psychological problems and particularly depression is one of the problems that menopausal women face in modern societies. Several studies reported that women are often at increased risk of

* Corresponding Author:

Shirin Farazmand, MSc.

Address: Department of Clinical Psychology, University of Social Welfare and Rehabilitation Sciences, Koodakyar Ave., Daneshjoo Blvd., Evin, Tehran, Iran. Tel: +98 (935) 8295036

E-mail: farazmand.sn@gmail.com 
depression when they reach midlife (Pearlstein, Rosen, \& Stone, 1997; Hay, Bancroft, \& Johnstone, 1994; Huffman \& Myers, 1999). For example, previous studies showed that $45 \%$ of women who referred for care at menopause clinics and experienced a natural menopause had reported different levels of depressive symptoms (Hay et al., 1994). Also, another investigation found that $65 \%$ of those women seeking medical consultation for menopausal symptoms reported different degrees of depression (Huffman \& Myers, 1999).

Different hypotheses have tried to explain the relationship between menopause and depressive symptoms. Menopausal symptoms hypothesis suggests that sweating and sleep disturbance cause malaise and fatigue, which leads to depressed mood (Strack, Argyle, Schwarz, 1991; Saunders \& Roy, 1999). Medical hypotheses propose that vasomotor symptoms cause neuropsychiatric symptoms such as depression. The dominance of biomedical model results in defining menopause as a biological event and ignoring psychosocial factors. Although, in most cases, some physiological and pathological changes create these problems during menopause, several studies have found that hormonal factors cannot entirely explain depressive symptoms during menopause (Wilson, 2016; Perz \& Ussher, 2008). Vasomotor symptoms and sexual difficulties can be predicted by menopausal status and hormonal factors; however, psychological symptoms such as depression are associated with psychosocial factors (Hunter, Battersby, \& Whitehead, 1986).

Thus, psychological hypothesis proposes that midlife stressors such as major life events, changes in family or work roles, expectations and attitudes about menopausal transition that come with middle age contribute to depressed mood. The attitude of women about menopause has an important role in the creation or elimination of the problems (Sarrel, 2012). In this regard, many women consider menopause as the release time because of the end of reproductive years, there will be no responsibility for children, or fear of pregnancy, so they feel more comfortable and seem to be more sexually active than before. However, for most women, this period brings up some concern, as it is a visible sign of aging and the end of their appeal (Sadock \& Sadock, 2007). In addition, approximately $25 \%$ of middle-aged women are caring of their parents and $57 \%$ of them are in the workforce (Rosenfeld, 1997).

Therefore, one of the most important factors that predicts depression in older ages is subjective evaluation of stressors (Hamarat, Thompson, Karen, Zabrucky, \& Kenneth, 2010). Lifestyle is a complex concept, comprising multiple personality variables that determine an individual's perceptions, understanding, beliefs of, and movement within the world in reaching their perceived goals (Adler, 1946; Dreikurs, 1953). Previous studies suggest that the personality construct of lifestyle plays an important role with regard to the stress responses. These personality constructs of lifestyle could have exert a major influence on how the person perceives his or her environment. As such, lifestyle appears to provide a basis for understanding specific reactions to interpersonally difficult situations and appears theoretically consistent with the Individual Psychology theory that puts emphasis on the function of lifestyle in the appraisal of life events (Santamaria, 2001). Kern and colleagues noted that lifestyle plays a central role in one's coping with and responses to stressful situations (Curlette, Kern, \& Wheeler, 1993). Thus, the cognitive role of lifestyle in the appraisal of stressors is found to be important, although little research in the literature has investigated its possible role in the cognitive appraisal of stressors such as menopausal transition.

Therefore, the subjective evaluation of stressors in menopausal women affect their life satisfaction. According to the previous studies, perceived stress is inversely related to life satisfaction (Chang, 2000; Hamarat et al., 2010). Life satisfaction is one of the most examined variables related to depression. Life satisfaction is defined as "a global cognitive judgmental evaluation of one's life' (Diener, 1984). Guney and colleges investigated the relationship between depression and life satisfaction and found that life satisfaction was significantly correlated with depression and hopelessness (Guney, Kalafat, \& Boysan, 2010). Furthermore, an association between low satisfaction with life and depressive symptoms in old age has been found in some cross-sectional studies (Demura $\&$ Sato, 2003). In other words, a central component of the phenomenology of depression is a pervasive sense of dissatisfaction. One study found substantial negative correlation between life satisfaction ratings and self-reported depression. Their findings indicated that low life satisfaction was a risk factor for depression (Strack, Argyle, \& Schwarz, 1991; Saunders \& Roy, 1999).

Therefore, in order to develop an effective and comprehensive treatment for depression in the context of menopause, understanding the multivariate correlates of depressive symptoms is necessary. In accordance with the studies indicating that the symptoms of depression in menopausal women is not just biomedical (Wilson, 2016; Perz \& Ussher, 2008), we should consider that reporting a cluster of symptoms of depression in middleaged women may be reflective of a psychological problem (Becker et al., 2001). Most prior investigations have 
focused on medical causes of depression in menopausal women, but cognitive mechanism has been ignored and many questions have left unanswered about development and psychological process of depression in menopause. Thus, the aim of this study was to investigate the mediating role of life-satisfaction in the relationship between subjective evaluation of stressors and depression in menopausal women.

\section{Methods}

This was a cross-sectional study. The study population comprised all women aged 47-58 years who worked at Shahid Beheshti Universities. The sample size according to the multiple regression model consisted of 5 participants per each item of independent variables of questionnaire. In this study, we had 26 items in independent variables of questionnaire, therefore our sample size consisted of 130 participants $(\mathrm{n}=130)$, who were selected by available sampling method. After obtaining permission from these universities, sampling procedure was done. Exclusion criteria were having an obvious mental disorder symptom according to the participant's self- report, consumption of specific drugs, and presenting invalid and incomplete information.

All participants were informed about the purposes of the study and received the instructions for filling out the questionnaire. Participants agreed to take part in the study on investigating the effect of menopause on the quality of their life. Then, they started to fill the questionnaires. Prior to conducting analyses, 13 questionnaires were removed because of missing information concerning menstruation, making their menopausal status unclear and 10 questionnaires were removed because of incomplete filling. Menopausal status at survey was determined by asking whether menstrual periods had stopped or not and how old they were. Our remained sample consisted of 107 women that were in late premenopausal (no menstrual period within the past 3 months but some menstrual bleeding within the past 12 months) and postmenopausal (no menstrual period within the past 12 months) states. Finally, data of 107 participants were used in analysis.

Beck depression inventory II (BDI-II, Beck, Steer, \& Garbin, 1988) was used to measure depression symptoms. BDI-II is a 21-item self-report questionnaire. This questionnaire was designed to assess levels of depression in non-clinical populations. Scores on each item range from 0 (low intensity) to 3 (high intensity), indicating different levels of severity of a particular symptom experienced over the last week. It has been demonstrated to be a valid and reliable measure of depression (Beck, et al., 1988). The internal consistency of BDI-II was 0.87 (Beck et al., 1988). The Persian version of BDI-II has high internal consistency (The Cronbach $\alpha=0.87$ ) and acceptable test-retest reliability $(\mathrm{r}=0.74)$ (Ghassemzadeh, Mojtabai, Karamghadiri, \& Ebrahimkhani, 2005).

The satisfaction with life scale (SWLS) (Diener, Emmons, Larsen, \& Griffin, 1985) was designed to measure respondents' overall or global satisfaction with their lives. SWLS comprises 5 items and measures on a 7-point Likert-type scale, ranging from 1 (strongly disagree) to 7 (strongly agree). Since, each item is scored from 1 to 7 , so the possible total score ranges from 5 (low satisfaction) to 35 (high satisfaction). The 2 months test-retest correlation coefficient was 0.82 , and coefficient $\alpha$ was 0.87 . Hence, SWLS has desirable psychometric properties (Diener et al., 1985). The Persian version of SWLS has high internal consistency (The Cronbach $\alpha=0.83$ ) and acceptable test-retest reliability $(\mathrm{r}=0.69)$ (Bayani, Koocheki, \& Goodarzi, 2007). The current sample also demonstrated adequate internal consistency (The Cronbach $\alpha=0.84$ ).

Kern lifestyle scale (KLS) is a 35-item survey instrument, developed by Kern on the basis of central concepts of individual psychology theory (Curlette et al., 1993). This is a questionnaire with a Likert-type response format. It consists of 5 subscales: control, perfectionism, need to please, self-esteem, and expectations (Kern, 2008). KLS was developed to obtain the information to help understand the individual's reactions in the stressful situations. KLS can be applied to determine the hidden way an individual interacts to situations. Total internal consistency reliability coefficient of KLS was found to be 0.96 for the total inventory. Test-retest reliability coefficient of the inventory for the complete scale was found to be 0.87 (Ozpolat Isgor \& Sezar, 2012). This scale in the current sample was also demonstrating good internal consistency (Cronbach $\alpha=0.82$ )

\section{Results}

Table 1 shows the mean and standard deviation of lifestyle, life satisfaction, and depression scores in menopausal women. At first, we examined multiple regression statistical assumption by checking for multivariate outliers with Mahalanobis distance. Based on the results, no cases were eliminated from the analysis. After that, we assessed collinearity statistics and our result showed that the tolerance of all predictors are far in excess of 0.01 , suggesting that multicollinearity is not a problem. Path analysis was used by multiple regression analysis with standard method (Enter) to determine the proportion of subjective 
Table 1. Mean and standard deviation of variables.

\begin{tabular}{ccc}
\hline Variable & Mean & SD \\
\hline Control & 22.34 & 4.84 \\
\hline Perfectionism & 20.01 & 3.01 \\
\hline Need to please & 24.74 & 3.74 \\
\hline Self-esteem & 37.46 & 5.63 \\
\hline Expectations & 17.41 & 8.81 \\
\hline Life satisfaction & 16.91 & 6.82 \\
\hline Depression & 67.88 & 12.04 \\
\hline
\end{tabular}

PRACTICE in
CLINICAL PSYCH LOGY

Table 2. Model summary of predicting menopause depression according to life styles.

\begin{tabular}{|c|c|c|c|c|c|c|}
\hline Model & $\mathbf{R}$ & $R^{2}$ & Adjusted $\mathbf{R}^{2}$ & SE & $\mathbf{F}$ & $P$ value \\
\hline 1 & 0.63 & 0.40 & 0.37 & 9.56 & 12.58 & 0.00 \\
\hline
\end{tabular}

Table 3. Coefficients of predicting menopause depression according to life styles.

\begin{tabular}{cccccc}
\hline & B & SE & Beta & T & P value \\
\hline Control & 1.21 & 0.20 & 0.48 & 6.04 & 0.00 \\
Perfectionism & -0.82 & 0.38 & -0.20 & -2.15 & 0.03 \\
Self-esteem & 0.42 & 0.20 & 0.20 & 2.12 & 0.03 \\
Expectations & -0.26 & 0.11 & -0.19 & -2.14 & 0.01 \\
\hline
\end{tabular}

PRACTICE in CLINICAL PSYCH $\odot$ LOGY

evaluation of stressors and life satisfaction in explaining the variance of depression of menopausal women. Results are summarized in (Tables 2, 3, 4, 5). When life styles entered, adjusted $\mathrm{R}^{2}$ was 0.40 , which means that $40 \%$ of the variance of depression in menopausal women could be explained by subjective evaluation of stressors and when life satisfaction was entered, adjusted $\mathrm{R}^{2}$ was 0.45 , i.e. $45 \%$ of the variance of depression in menopausal women could be explained by life satisfaction.

At the next step, lifestyle subscales and life satisfaction were added to the regression simultaneously and adjusted $\mathrm{R}^{2}$ rose to 0.53 , which means that subjective evaluation of stressors and life satisfaction can explain $53 \%$ of the variance of depression in menopausal women. The path analyses in this study supported the hypothesis that life satisfaction mediates the relationship between subjective evaluation of stressors and depression among menopausal women. For each endogenous variable, we conducted a multiple regression analysis by Enter method to check that subjective evaluation of stressors and life satisfaction variables affect depression variable. The beta weights from these multiple regressions were the path coefficients shown in the typical figures used to display the results of path analysis. Our diagram indicated that depression in menopausal women is directly affected by control sub-

Table 4. Model summary of predicting menopause depression according to life styles and life satisfaction.

\begin{tabular}{ccccccc}
\hline Model & $\mathbf{R}$ & $\mathbf{R}^{2}$ & Adjusted $\mathbf{R}^{2}$ & $\mathbf{S E}$ & $\mathbf{F}$ & P value \\
\hline 2 & 0.74 & 0.56 & 0.53 & 8.27 & 19.45 & 0.00 \\
\hline
\end{tabular}


Table 5. Coefficients of predicting menopause depression according to life styles.

\begin{tabular}{cccccc} 
& B & SE & Beta & T value & 0.00 \\
\hline Control & 0.74 & 0.19 & 0.29 & 3.88 & -2.57 \\
Perfectionism & -0.57 & 0.22 & -0.25 & 2.80 & 0.01 \\
Self-esteem & 0.32 & 0.11 & 0.27 & -5.71 & 0.00 \\
Life satisfaction & -0.87 & 0.15 & -0.49 & &
\end{tabular}

PRACTICE in CLINICAL PSYCH $\mathbb{L}$ LOGY

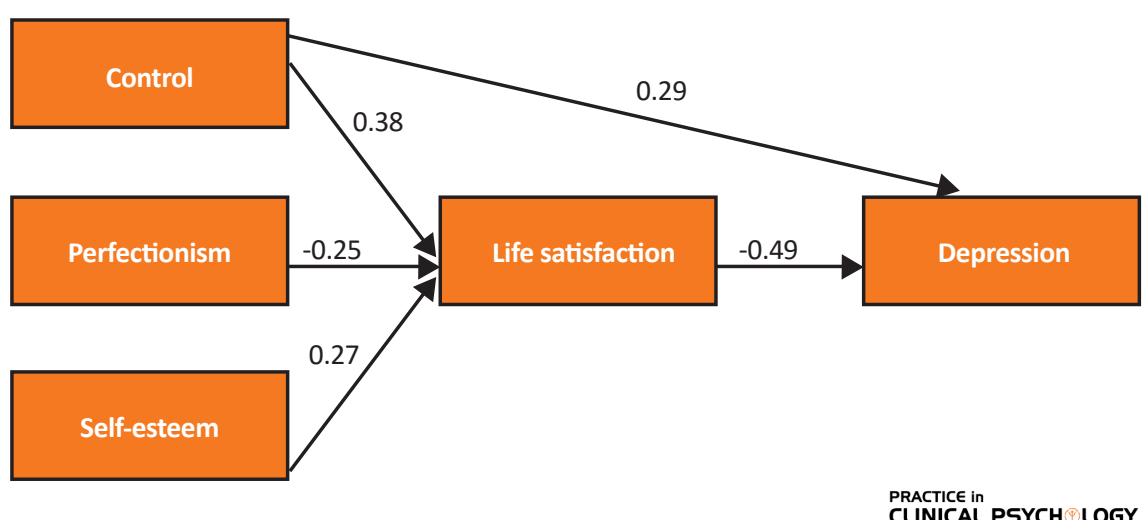

Figure 1. Path analysis model for explaining depression in menopausal women based on lifestyle and life satisfaction.

scale and indirectly by control, self-esteem, and perfectionism through mediating life satisfaction. We used two multiple regression by standard method (Enter) and obtained adjusted $\mathrm{R}^{2}=0.53$ and the beta weights (Figure 1).

\section{Discussion}

The present study aimed to investigate the mediating role of life satisfaction in the relationship between subjective evaluation of stressors and depression in menopausal women. Results demonstrated that the control, perfectionism, and self-esteem lifestyles predicted life satisfaction and depressive symptoms in middle-aged menopausal women. These results are consistent with previous studies reporting that subjective evaluation of stressors are related to life satisfaction and depression (Guney et al., 2010; Saunders \& Roy, 1999; Flett, Hewitt, Blankstein, \& O’Brien, 1991; Talaei, Fayyazi, \& Rezaei, 2009; Chen, Cheung, Bond, \& Leung, 2006). Prior studies also referred to the fact that menopausal women are more likely to experience depression (Hay et al., 1994; Huffman \& Myers, 1999; Hunter, 1990). The prevalence of depression of menopausal women in this study was $41.8 \%$. In particular $28.6 \%$ had mild depression, $11.2 \%$ moderate depression, and $2 \%$ severe depression. It is important to notice that psychological problems during menopause are not only hormonal but also psychosocial factors contribute to middle-aged menopausal depression (Rosenfeld, 1997; Hunter et al., 1986).

Considering previous studies, one of these psychological factors is subjective evaluation of stressors. Objective sources of menopausal women stress (stressors) can be considered only as the potential sources of stress. These sources can lead to the real stress if the menopausal women perceives them as the threats to satisfaction of their fundamental needs, such as being ideal, fulfilling all their requirements, avoiding mistakes, and receiving recognition of others. Therefore, the subjective evaluation of stressors is the result of the frustration of these needs. Lack of possibilities to fulfill the needs of lifestyle in menopausal women endangers their self-concept and as a result, leads to the negative emotions and reduces their life-satisfaction. Feeling of failure influences their self-esteem and sense of self in general.

Among menopausal women, 3 lifestyles are predictors, i.e. perfectionism, control, and self-esteem. According to Adler's view on lifestyles, these individuals in order to rise their self-esteem, to increase the feelings of own significance, to experience acceptance with society and belonging to this society unconsciously make a decision in favor 
of "I have to be perfect" and "I have to handle all life's problems". Thus, we can see how these lifestyles influence the development of stress when a perfectionist and a person who wants to be in control enters the menopausal period and encounters with changes that occurs in middle age.

Our findings also showed that control-oriented lifestyle in menopausal women is the predictor of life satisfaction and as a result depressive symptoms. Our study results are consistent with some previous studies which suggest that the high incidence of depression among midlife women may be in part a response to their attempts to cope with significant new life challenges they face in menopausal period. These challenges lower their feelings of control over their lives and individuals who feel more control over their situations feel more satisfied with their lives. In addition, these challenges may affect overall life satisfaction during the middle years (Aldwin \& Levenson, 2001). From the lifestyle perspective and with respect to these findings, it can be argued that individuals who think that have more control, feel better in their lives. The lifestyle, which is adopted by an individual is an important part of individual's response to stress. As a result, it can be claimed that during stressful situations, people's lifestyle affect their interpretation and satisfaction with their lives.

This study has also some implications for healthcare providers who address only the hormonal problems of menopausal women and ignore other dimensions of their wellbeing. Because of huge burden on middleaged women, finding new strategies for relieving their depressive symptoms is crucial. However, most previous studies focus on biological factors and few studies have investigated the related psychological factors with menopause, which identify the fundamental cognitive processes involved in depression during menopausal transition. Furthermore, by investigating women's subjective evaluation of stressors with lifestyle types, it might be possible to gain an insight into the cognitive processes, which are in operation when they experience menopause. Therefore, considering the effects of psychosocial factors on menopause is crucial.

The present study has some limitations too. First of all, it was a correlational study, so we cannot infer causal relationships about the findings. Second, since the study sample included menopausal women living in one city, generalization of these findings to all menopausal women is limited. Moreover, the data were collected using self-report instruments that should be considered. Future research should examine these results with broader populations that was not included in this study. Additional research is need- ed to determine whether this conclusion could be generalized to all menopausal women. To this end, future studies should examine the relationship between subjective evaluation of stressors, life satisfaction, and depression in menopausal women in different cultural groups that may help to generalize the findings of this study.

\section{Acknowledgments}

The authors are sincerely grateful to all study participants and those who helped us in conducting this research. The current research hasn't received any financial support.

\section{Conflict of Interests}

The authors declared no conflict of interests.

\section{References}

Adler, A. (1946). The practice and theory of individual psychology. New York: Paul \& Trubner Ltd.

Adler, A. (1956). The individual psychology of Alfred Adler: a system atic presentation in selections from his writings. New York: Basic Books Publication.

Aldwin, M., \& Levenson, M. (2001). Stress, coping, and health at midlife: A developmental perspective. In M. E. Lachman (Ed.), Handbook of Midlife Development (pp. 188-213). New York: John Wiley \& Sons.

Bayani, A. A., Goodarzi, H., \& Koocheki, A. (2007). The reliability and validity of the satisfaction with life scale. Developmental Psychology, 3(11), 259-65.

Baron, R. M., \& Kenny, D. A. (1986). The moderator-mediator variable distinction in social psychological research: conceptual, strategic, and statistical considerations. Journal of Personal Socio Psychology, 51(6), 1173-182.

Beck, A. T., Steer R. A., \& Garbin M. G. (1988). Psychometric properties of the beck depression inventory: twenty-five years of evaluation. Clinical Psychology Review, 8(1), 77-100.

Becker, D., Lomranz, J., Pines, A., Shmotkin, D., Nitza, E., Bennamitay, G., et al. (2001). Psychological distress around menopause. Psychosomatics, 42(3), 252-57.

Bromberger, J. T., Harlow, S., Avis, N., Kravitz, H. M., \& Cordal, A. (2004). Racial/ethnic differences in the prevalence of depressive symptoms among middle-aged women: the study of women's health across the nation. American Journal of Public Health, 94(8), 1378-385.

Bonnet, F., Irving, K., Terra, J., Nony, P., \& Moulin, P. (2005). Anxiety and depression are associated with unhealthy lifestyle. Journal of Atherosclerosis, 178(2), 339-44.

Bromberger, J. T., Schott, L. L., Kravitz, H. M., Sowers, M., Avis, N. E., Gold, E. B., et al. (2010). Longitudinal change in reproductive hormones and depressive symptoms across the men- 
opausal transition: results from the study of women's health across the nation. Archives of General Psychiatry, 67(6), 598-607.

Chandler, C. K. (1986). Validation of the Adlerian construct of perceived early childhood family influences (PhD thesis). Texas: Texas Technology University.

Chang, E. C. (2000). Perfectionism as a predictor of positive and negative psychological outcomes: examining a mediation model in younger and older adults. Journal of Counseling Psychology, 47(1), 18-26.

Chen, S. X., Cheung, F. M., Bond, M. H., \& Leung, J. P. (2006) Going beyond self-esteem to predict life satisfaction: the Chinese case. Asian Journal of Social Psychology, 9(1), 24-35.

Cohen, L. S., Soares, C. N., Poitras, J. R., Prouty, J., Alexander, A. B., \& Shifren, J. L. (2003). Short-term use of estradiol for depression in perimenopausal and postmenopausal women: a preliminary report. American Journal of Psychiatry, 160(8), 1519-522.

Curlette, W. L., Kern, R. M., \& Wheeler, M. S. (1993). BASIS-an inventory interpretive manual: a psychological theory. North Carolina, USA: TRT Associates Publication.

Demura, S., \& Sato, S. (2003). Relationships between depression, lifestyle and quality of life in the community dwelling elderly: a comparison between gender and age groups. Journal of Physiological Anthropology and Applied Human Science, 22(3), 159-66.

Diener, E. (1984). Subjective well-being. Psychological Bulletin, 95(3), 542-75.

Diener, E. D., Emmons, R. A., Larsen, R. J., \& Griffin, S. (1985). The satisfaction with life scale. Journal of Personality Assessment, 49(1), 71-75.

Dreikurs, R. (1953). Fundamentals of Adlerian psychology. Chicago, I.L.: Alfred Adler Institute.

Enns, M. W., \& Cox, B. J. (1999). Perfectionism and depression symptoms severity in major depressive disorder. Behavior Research and Therapy, 37(8), 783-94.

Extremera, N., \& Fernandez-Berrocal, P. (2002). Relation of perceived emotional intelligence and health-related quality of life of middle-aged women. Psychological Reports, 91(1), 47-59.

Flett, G. L., Hewitt, P. L., Blankstein, K., \& O’Brien, S. (1991). Perfectionism and learned resourcefulness in depression and self-esteem. Personality and Individual Differences, 12(1), 61-68.

Ghassemzadeh, H., Mojtabai, R., Karamghadiri, N., \& Ebrahimkhani, N. (2005). Psychometric properties of a Persianlanguage version of the Beck Depression Inventory-Second edition: BDI-I-II-PERSIAN. Depress Anxiety, 21(4), 185-92.

Greendale, G. A, Lee, N. P., \& Arriola, E. R. (1999). The menopause. Lancet, 353(9152), 571-80.

Guney, S., Kalafat, T., \& Boysan, M. (2010). Dimensions of mental health: life satisfaction, anxiety and depression: a preventive mental health Study in Ankara University. ProcediaSocial and Behavioral Sciences, 2(2), 1210-213. doi:10.1016/j. sbspro.2010.03.174

Hamarat, E., Thompson, D., Karen, M., Zabrucky D., \& Kenneth, B. (2001). Perceived stress and coping resource availability as predictors of life satisfaction in young, middle-aged, and older adults. Experimental Aging Research, 27(2), 181-96.
Hay, A. G., Bancroft, J., \& Johnstone, E. C. (1994). Affective symptoms in women attending a menopause clinic. British Journal of Psychiatry, 164(4), 513-16.

Huffman, S. B., \& Myers, J. E. (1999). Counseling women in midlife: an integrative approach to menopause. Journal of Counseling and Development, 77(3), 258-65.

Hunter, M., Battersby, R., \& Whitehead, M. (1986). Relationships between psychological symptoms, somatic complaints and menopausal status. Maturitas, 8(3), 217-28.

Hunter, M. S. (1990). Psychological and somatic experience of the menopause: a prospective study. Psychosomatic Medicine, 52(3), 357-367.

Ingeborg, A. (2008) Life satisfaction in late life (PhD thesis). Sweden: University of Guthenburg.

Kern, R. M. (2008). Lifestyle assessment on tenderness and aggression. Paper presented at International Congress of Individual Psychology, Vilnius, Lithuania, 31 July-3 August 2008.

Li, C., Borgfeldt, C., Samsioe, G., Lidfeldt, J., \& Nerbrand, C. (2005). Background factors influencing somatic and psychological symptoms in middle-age women with different hormonal status: a population-based study of Swedish women. Maturitas, 52(3), 306-18.

Lippert, L. (1997). Women at midlife: implications for theories of women's adult development. Journal of Counseling and Development, 76(1), 16-22.

Wang-Cheng, R., Neuner, J. M., \& Barnabei, V. M. (2007). Menopause. Philadelphia: ACP Press.

Meyer, R. G., \& Deitsch, S. E. (1996). Clinician's handbook: integrated diagnostics, assessment, and intervention in adult and adolescent psychopathology (4 $4^{\text {th }}$ ed.). Boston: Allyn \& Bacon.

Moilanen, J., Aalto, A. M., Hemminki, E., Aro, A. R., Raitanen, J., \& Luoto, R. (2010). Prevalence of menopause symptoms and their association with lifestyle among Finnish middle-aged women. Maturitas, 67(4), 368-74.

Ozpolat, A. R., Isgor, I. Y., \& Sezer, F. (2012). Investigating psychological well being of university students according to lifestyles. Procedia-Social and Behavioral Sciences, 47, 256-62.

Pearlstein, T., Rosen, K., \& Stone, A. B. (1997). Mood disorders and menopause. Endocrinology Metabolism Clinics of North America, 26(2), 279-94.

Pedhazur, E. J. (1982). Multiple regression in behavioral research: explanation and prediction ( $2^{\text {nd }}$ ed.). New York: Holt, Rinehart and Winston.

Perz, J., \& Ussher, J. M. (2008). The horror of this living decay: Women's negotiation and resistance of medical discourses around menopause and midlife. Women's Studies International Forum, 31(4), 293-99.

Rosenfeld, J. A. (1997). Women's health in midlife. Cambridge: Cambridge University Press.

Ross, R., Zeller, R., Srisaeng, P., Yimmee, S., Somchid, S., \& Sawatphanit, W. (2005). Depression, stress, emotional support, and self-esteem among baccalaureate nursing students in Thailand. International Journal of Nursing Education Scholarship, 2(1), 11-24. 
Sadock, J. B., \& Sadock, A. V. (2007). Comprehensive textbook of psychiatry $\left(7^{\text {th }} \mathrm{ed}\right)$. New York: Lippinocott Williams \& Wilkins.

Sarrel, P. M. (2012). Women, work, and menopause. Menopause, 19(3), 250-52.

Saunders, S. A., \& Roy, C. (1999). The relationship between depression, satisfaction with life, and social interest. South Pacific Journal of Psychology, 11(1), 9-15.

Santamaria, N. (2001). The relationship between nurses' personality and stress levels reported when caring for interpersonally difficult patients. Australian Journal of Advanced Nursing, 18(2), 20-26.

Strack, F., Argyle, M., \& Schwarz, N. (1991). Subjective well-being: an interdisciplinary perspective. Oxford: Pergamon Press.

Stoeber, J., \& Stoeber, F. S. (2009). Domains of perfectionism: prevalence and relationships with perfectionism, gender, age, and satisfaction with life. Personality and Individual Differences, $46(4), 530-35$.

Talaei, A., Fayyazi, M., \& Rezaei, A. (2009). Depression and its correlation with self-esteem and social support. Iran Journal of Psychiatry, 4(1), 17-22.

Van Gool, C. H., Kempen, G. I., Penninx, B. W., Deeg, D. J., Beekman, A. T., \& Van Eijk, J. T. (2003). Relationship between changes in depressive symptoms and unhealthy lifestyles in late middle aged and older persons: results from the Longitudinal Aging Study Amsterdam. Age and Ageing, 32(1), 81-87.

Van Gool, C. H., Kempen, G. I., Bosma, H., van Boxtel, M. P., Jolles, J., \& Van Eijk, J. T. (2007). Associations between lifestyle and depressed mood: longitudinal results from the Maastricht aging study. American Journal of Public Health, 97(5), 887-94.

Walsh, R. (2011). Lifestyle and mental health. American Psychologist, 66(7), 579-92. doi: 0.1037/a0021769

Wattis, J., \& Curran, S. (2009). Lifesyle and depression. In N. Cooper, K. Forrest \& G. Mulley (Eds.), ABC of Geriatric Medicine (pp. 570-73). Oxford: BMJ Books.

Wilson, C. (2016). Menopause? I think I'll pass. New Scientist, 229(3054), 8-9. 